\title{
Requests for euthanasia in general practice before and after implementation of the Dutch Euthanasia Act
}

\author{
Jojanneke E van Alphen, Gé A Donker and Richard L Marquet
}

\author{
ABSTRACT \\ Background \\ The Netherlands was the first country in the world to \\ implement a Euthanasia Act in 2002. It is unknown \\ whether legalising euthanasia under strict conditions \\ influences the number and nature of euthanasia \\ requests. \\ Aim \\ To investigate changes in the number of, and reasons \\ for, requests for euthanasia in Dutch general practice \\ after implementation of the Euthanasia Act.

\section{Design of study} \\ Retrospective dynamic cohort study comparing 5 years \\ before (1998-2002) and 5 years after (2003-2007) \\ implementation of the Act.

\section{Method} \\ Standardised registration forms were used to collect \\ data on requests for euthanasia via the Dutch Sentinel \\ Practice Network. This network of 45 general practices \\ is nationally representative by age, sex, geographic \\ distribution, and population density.

\section{Results} \\ The mean annual incidence of requests before \\ implementation amounted to $3.1 / 10000$ and thereafter \\ to $2.8 / 10000$ patients. However, trends differed by sex. \\ The number of requests by males decreased \\ significantly from $3.7 / 10000$ to $2.6 / 10000(P=0.008)$; \\ the requests by females increased non-significantly \\ from 2.6/10 000 to $3.1 / 10000$. Before and after \\ implementation, cancer remained the major underlying \\ disease for requesting euthanasia: $82 \%$ versus $77 \%$ \\ for men; $73 \%$ versus $75 \%$ for females. Pain was a \\ major reason for a request, increasing in the period \\ before implementation (mean $27 \%$ ), but declining in the \\ period thereafter (mean 22\%). Loss of dignity became \\ a less important reason after implementation (from \\ $18 \%$ to $10 \%, P=0.04$ ), predominantly due to a \\ marked decrease in the number of females citing it as \\ a reason (from $17 \%$ to $6 \%, P=0.02$ ).

\section{Conclusion} \\ There was no increase in demand for euthanasia after \\ implementation of the Euthanasia Act. Pain as a reason \\ for requesting euthanasia showed an increasing trend \\ before implementation, but declined thereafter. Loss of \\ dignity as a reason declined, especially in females. \\ Keywords \\ death; epidemiology; euthanasia; euthanasia Act; \\ family practice; legislation; palliative care.
}

\section{INTRODUCTION}

An earlier paper reported on the number of requests for euthanasia occurring in Dutch general practice between 1977 and 2001. ${ }^{1}$ The main finding was that after a steep rise during the first 20 years of registration, the number of requests, predominantly by patients with terminal cancer, stabilised. It was also observed that hopelessness and deterioration were relatively constant reasons for a request, whereas pain and dyspnoea were gradually decreasing reasons. Others have shown that, apart from pain, depressive symptoms and dependency are frequent reasons for a request. . $^{2,3}$ It is known that most requests for euthanasia do not result in their actual completion, because either the patient dies naturally, or the physician considers the request not eligible, or a request is withdrawn. ${ }^{4,5}$ It is noteworthy that, in particular, patients with depressive symptoms and (fear of) pain may change their mind over time. ${ }^{2}$

In 2002, euthanasia and physician-assisted suicide were legalised in the Netherlands by the passing of the Euthanasia Act. This was intended to make an already existing practice more transparent and to offer legal protection for the physician involved, provided strictly defined requirements for careful practice were met. ${ }^{6,7}$ Recent studies have shown that

JE van Alphen, $P h D, M D$, medical student, University of Utrecht, The Netherlands. GA Donker, MD, PhD, GP, epidemiologist, project leader Dutch sentinel stations; RL Marquet, $M D, P h D$, senior researcher, NIVEL (Netherlands Institute for Health Services Research), Utrecht, The Netherlands.

Address for correspondence

Dr Gé A Donker, NIVEL, PO Box 1568, 3500 BN Utrecht, The Netherlands. E-mail: g.donker@nivel.nl

Submitted: 28 September 2009; Editor's response: 25 November 2009; final acceptance: 27 January 2010.

(c)British Journal of General Practice 2010; 60: 263-267.

DOI: 10.3399/bjgp10X483931 


\section{How this fits in}

Pain is the most frequent reason for requesting euthanasia. Depressive symptoms and dependency are also frequent reasons for a euthanasia request. There was no increase in demand for euthanasia after implementation of the Euthanasia Act. The Act provided a framework for developing professional guidelines enhancing compliance to the criteria allowing euthanasia.

the Act has not resulted in the often feared slippery slope; on the contrary, the number of deaths in the Netherlands due to euthanasia decreased from 2.6\% of all deaths in 2001 to $1.7 \%$ in 2005. Physicianassisted suicide declined from $0.2 \%$ in 2001 to $0.1 \%$ in 2005. Improved palliative care, including the use of deep continuous sedation at the end of life, is a possible explanation for this decrease. ${ }^{8}$

Nevertheless, an interesting question remains, namely whether implementation of the Euthanasia Act has influenced the number of requests for euthanasia and/or may have led to changes in the underlying reasons for such a request. These subjects, and possible differences by sex, are addressed in the current study. This research aimed to compare the requests for euthanasia posed over the 5 years before implementation with requests over the 5 years after implementation, using data from the Dutch Sentinel Practice Network.

\section{METHOD}

Data on requests for euthanasia or physician-assisted suicide (collectively called euthanasia hereafter and not further addressed separately because of the very low number of physician-assisted suicides), have been collected by GPs participating in the Dutch Sentinel Practice Network since 1977. The Network consists of about 45 general practices (61 GPs) covering about $1 \%$ of the Dutch population, and is nationally representative with respect to age, sex, geographic distribution, and population density. ${ }^{9-11}$ Over $95 \%$ of non-institutionalised citizens in the Netherlands are registered with a GP. A census is held annually among the practice populations involved to determine the size and composition of the population to which the collected data are to be related. The Dutch Sentinel Practice Network has been participating in many national and international projects, the oldest international project being the European Influenza Surveillance Scheme, currently run by the European Centre for Disease Control. ${ }^{12,13}$ GPs participating in the network report weekly to the Netherlands Institute for Health Services Research on the incidence of various diseases and interventions, including suicide or suicide attempts and requests for euthanasia, ${ }^{1,9,11}$
In the current study, the data on requests for euthanasia gathered between 1998 and 2007 were analysed. GPs reported the number of and reasons for requests for euthanasia encountered in their practice. Only serious requests by terminally ill patients were noted. Requests for possible euthanasia in the future, not related to an existing condition, were excluded. Age, sex, underlying disease, reason for the request, and the presence of a living will were recorded on the questionnaire. Incidences of requests were calculated as the number of requests per 10000 patients on GPs' lists. Requests by males and females were also analysed separately. Diseases were classified using the International Classification of Primary Care system. Reasons for requesting euthanasia were classified into different subcategories: pain, dyspnoea, unbearable suffering, hopelessness, and loss of dignity. They were converted into incidences per number of requests. Most patients expressed more than one reason. The 5-year period before implementation of the Euthanasia Act (1998-2002) was compared with the 5-year period after implementation (2003-2007). Although the Act was passed in 2002, 2002 was considered to be a year in which the Act was not yet implemented in practice.

Analyses of statistical differences between parameters before and after implementation, as presented in Table 1, were performed using the Wilcoxon two-sample test. Trends in the number of requests and the underlying reasons were visualised in Excel by grade-2 polynomal trend lines (Figures 1 and 2).

\section{RESULTS}

\section{Number of requests for euthanasia}

In the 5-year period preceding implementation of the Euthanasia Act, the number of requests showed a decreasing trend; after implementation, the number of requests remained stable (Figure 1). Nonetheless, the mean overall annual incidences before and after implementation were not significantly different, and amounted to $3.1 / 10000$ and $2.8 / 10000$, respectively. However, the trends for males and females showed a different pattern: the mean number of requests by males decreased significantly from $3.7 / 10000$ to 2.6/10 000 (Table 1; $P=0.008$ ), whereas the mean number of requests by females increased (not significantly) from 2.6/10 000 to $3.1 / 10000$.

\section{Underlying disease}

Both before and after implementation, cancer was the major underlying disease leading to a request for euthanasia. The mean incidence for the whole 10 -year period of investigation was $79 \%$ for males (range 69-89\%) and 73\% (range 65-81\%) for females $(P=0.07)$. There were no significant differences 


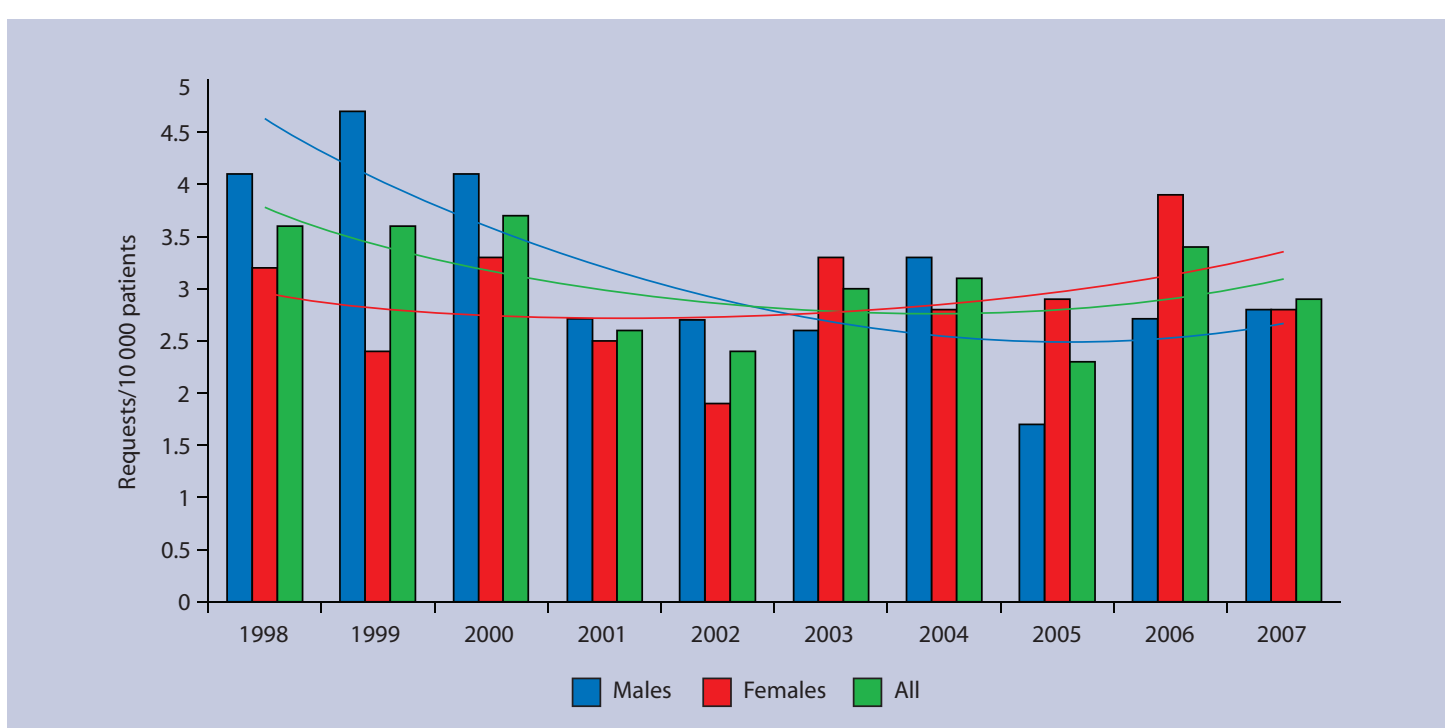

between the 5-year periods before and after implementation, for either males or females (Table 1).

Other less important reasons for a euthanasia request were cardiovascular disease, chronic obstructive pulmonary disease (COPD), neurodegenerative diseases, and severe depression - showing mean incidences by category between $2 \%$ and $4 \%$ (Table 1). Results suggest that cardiovascular disease has become a less important reason and COPD a more important reason for a request; however, the differences are not statistically significant. Stratification by sex was not meaningful because of the small numbers.

\section{Underlying reasons}

Pain was a major reason for a request for euthanasia (Figure 2), showing an increasing trend before implementation and a decreasing trend thereafter, predominantly due to a decrease in the number of females citing it as a reason $(P=0.1)$. The mean overall incidences before and after implementation were not significantly different and amounted to $27 \%$ and $22 \%$, respectively (Table 1 ).

Both unbearable suffering and, to a lesser extent, dyspnoea showed an upward trend after 2002, but, similar to hopelessness and pain, differences between the mean incidences before and after implementation were not statistically significant.

By contrast, loss of dignity showed a significant downward trend over time and became a less important reason for requesting euthanasia, especially for females. The overall mean incidence decreased from $18 \%$ before to $10 \%$ after implementation $(P=0.04)$. For females, the

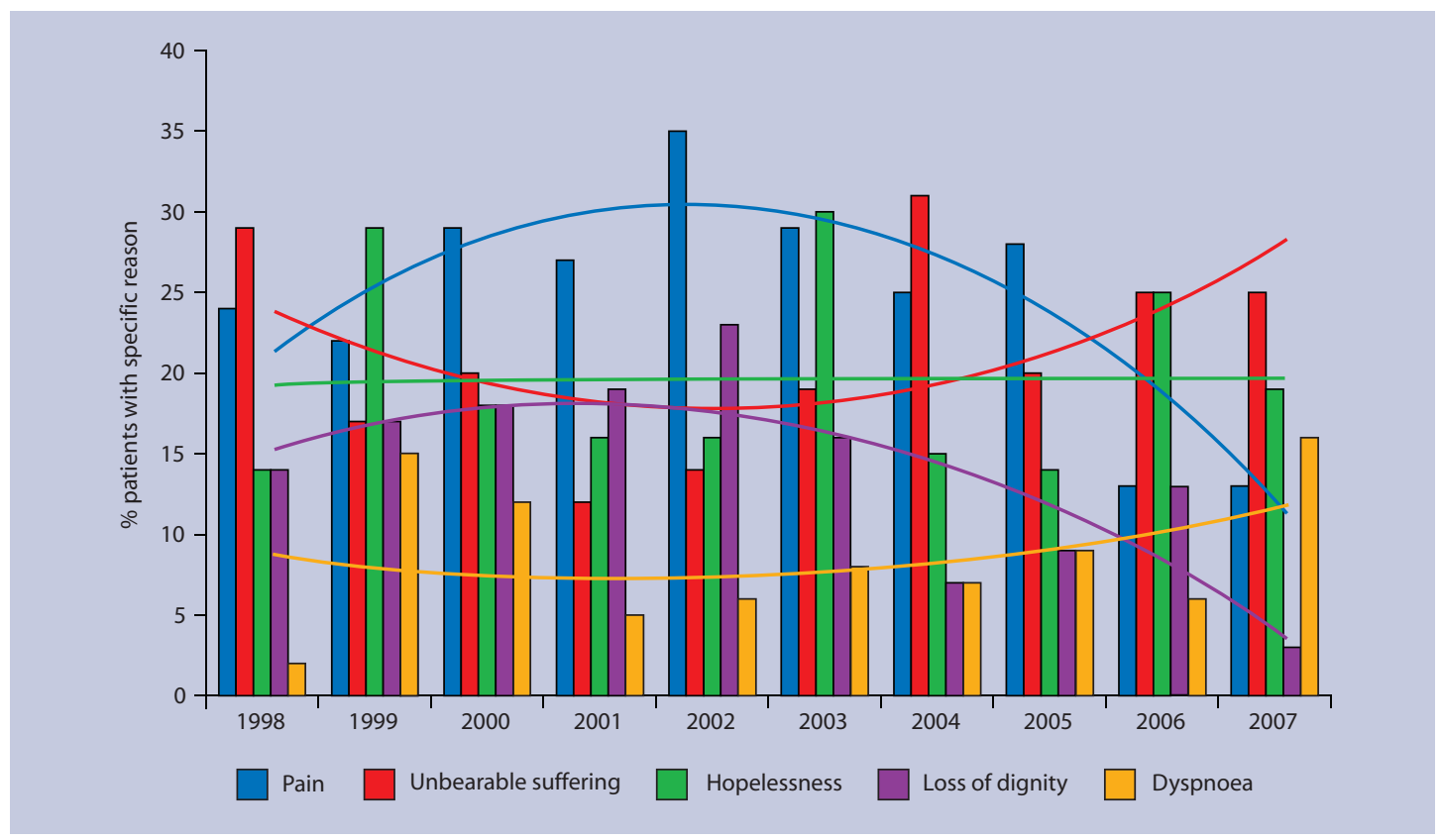

Figure 1. Requests for euthanasia in Dutch general practice 1998-2007; trends in incidence. 
Table 1. Requests for euthanasia and reasons for these requests during 5 years before (1998-2002) and 5 years after (2003-2007) implementation of the Euthanasia Act in the Netherlands.

\begin{tabular}{|c|c|c|c|c|c|c|c|}
\hline & \multicolumn{2}{|c|}{ Males } & \multicolumn{2}{|c|}{ Females } & \multicolumn{2}{|c|}{ Total } & \multirow[b]{2}{*}{$P$-value } \\
\hline & Before & After & Before & After & Before & After & \\
\hline Requests $/ 10000^{a}$ & $3.7^{\mathrm{b}}$ & $2.6^{b}$ & 2.6 & 3.1 & 3.1 & 2.8 & ${ }^{\mathrm{b}} P<0.01$ \\
\hline \multicolumn{8}{|l|}{ Diseases, \% } \\
\hline Cancer & 82 & 77 & 73 & 75 & 78 & 77 & \\
\hline Cardiovascular diseases & & & & & 3.6 & 2.7 & \\
\hline Severe depression & & & & & 3.1 & 3.8 & \\
\hline ALS/MS/muscular dystrophy & & & & & 2.7 & 2.7 & \\
\hline COPD & & & & & 2.3 & 3.8 & \\
\hline \multicolumn{8}{|l|}{ Reasons, \% } \\
\hline Pain & 23 & 23 & $32^{\circ}$ & $22^{\circ}$ & 27 & 22 & \\
\hline Unbearable suffering & 17 & 21 & 18 & 27 & 18 & 24 & \\
\hline Hopelessness & 19 & 22 & 20 & 20 & 19 & 21 & \\
\hline Loss of dignity & 20 & 15 & $17^{\circ}$ & $6^{c}$ & $18^{\mathrm{d}}$ & $10^{d}$ & $\begin{array}{l}{ }^{\mathrm{C}} P<0.05 \\
{ }^{\mathrm{d}} P<0.05\end{array}$ \\
\hline Dyspnoea & 8 & 7 & 7 & 10 & 8 & 9 & \\
\hline
\end{tabular}

$A L S=$ amyotrophic lateral sclerosis. COPD = chronic obstructive pulmonary disease. $M S=$ multiple sclerosis. ${ }^{a}$ Requests are given as mean incidence/10 000 patients; all other entries are given as mean percentage of patients with a certain disease or expressing a specified reason for a request. ${ }^{b, c, d} \mathrm{P}$-value, statistical significance according to the Wilcoxon two-sample test.

corresponding percentages were $17 \%$ and $6 \%$ $(P=0.02)$ and for males $20 \%$ and $15 \%(P=0.6)$.

\section{DISCUSSION}

\section{Summary of main findings}

The major finding of the current study is that the implementation of the Euthanasia Act in 2002 has not led to a significant increase in the number of requests for euthanasia. In an earlier study before implementation of the Euthanasia Act, Marquet et al reported that the number of requests for euthanasia in the Netherlands steadily increased between 1977 and 1995, but subsequently stabilised. ${ }^{1}$ The current study indicates that this plateau has remained unchanged since 2002. It should be noted that implementation of the Act took place after extended political and media discussions and, therefore, may have been a formalisation of an already existing practice rather than a turning point in attitudes. Although overall there were no significant differences between the number of requests in the 5-year periods before and after implementation of the Euthanasia Act, some peculiar trend differences by sex were revealed. This finding should not be overstated, but it might imply that implementation of the Euthanasia Act helped females more than males to communicate a wish for euthanasia to their GP.

Cancer remained the predominant underlying reason for a request throughout the whole 10-year period of investigation. Cardiovascular disease seems to have become a less frequent and COPD a more frequent reason for a request for euthanasia, possibly reflecting recent trends in the incidence and mortality of these diseases. ${ }^{14}$

Pain was a major reason for requesting euthanasia.
The authors have reported previously that in the early years of registration (1977-1987), pain was indicated by $50 \%$ of the patients as a reason for a request. This percentage gradually decreased to about $25 \%$ in the following decade, ${ }^{1}$ probably as a result of improved palliative care and the professionalised management of pain. In the current study it was found that the pain factor remained at the $25 \%$ level, showing no significant differences between the 5-year period before and after implementation of the Euthanasia Act, albeit that in recent years pain as a reason for a request seemed to decrease again. It is quite possible that the growing use of continuous deep sedation in the Netherlands to cope with pain, anxiety, and dyspnoea in the terminal phase of life is responsible for this decrease. ${ }^{8,15}$ This theory is supported by the finding that the use of continuous deep sedation in the Netherlands increased from $5.6 \%$ of deaths in 2001 to $7.1 \%$ in 2005, mostly in patients treated by GPs. ${ }^{8}$ The Dutch Sentinel stations did not find an increase in the application of palliative sedation in more recent years. ${ }^{9}$

Unbearable suffering was used in the current investigation as a separate item, although it is actually a general term (just like the term hopelessness), covering the multiple reasons for a request for euthanasia. It should be noted that in the Dutch Euthanasia Act, unbearable suffering is a major decisive factor for allowing euthanasia. ${ }^{6}$ In the present study, no significant difference was found in the degree of unbearable suffering between the periods before and after implementation of the Euthanasia Act. Nevertheless, after 2002 an upward trend was noticed, possibly indicating that GPs used the term more frequently, or more consistently, to comply with the regulations laid down in the Euthanasia Act. It is 
not surprising that hopelessness as reason for a request was of the same magnitude and followed an almost similar course to that of unbearable suffering.

During the 10-year period of investigation, loss of dignity as a reason for a request for euthanasia became less important, and this was observed predominantly in females. It has been discussed earlier that loss of dignity is a major concern of dying patients and constitutes one of the main motivations behind efforts to improve palliative care and promote the goal of a good death. ${ }^{16}$ In the Netherlands, palliative care has improved considerably in the past decade, mainly due to the efforts of the Network of Palliative Care for Terminal Patients. ${ }^{17}$ Guidelines for palliative care are increasingly being implemented in hospitals, nursing homes, general practice, and hospices. It is therefore possible that improvements in the practice of palliative care constitute an important reason why loss of dignity has become a less important reason for a request for euthanasia. Why this trend was more outspoken in females than in men is a puzzle. Males and females may perceive loss of dignity differently. For males, loss of dignity is probably more related to loss of control than for females. It is conceivable that females have become more convinced than males that the availability of palliative care guarantees that the road towards dying can be walked with dignity.

\section{Strengths and limitations of the study}

This study provides a unique evaluation of the impact of euthanasia legislation on the number of and reasons for euthanasia requests and shows that a demand for euthanasia persists despite good palliative care. Stemming from the time when euthanasia was not yet legalised, this study analysed euthanasia requests: not just executed euthanasia. This is a limitation of our study. Other studies report that $44 \%$ of the requests are executed. ${ }^{4,5}$

\section{Comparison with existing literature}

From another Dutch evaluation of the Euthanasia Act, it is known that extra information was required from the GP in less than $6 \%$ of annually reported euthanasia interventions in 2000, but in the years 2003-2005 none of these further investigations led to prosecution. ${ }^{18}$ Thus, consistent with the present study, the evaluation did not provide any evidence of failure to adhere to the strict criteria laid down in the Dutch Euthanasia Act.

\section{Implications for clinical practice}

The Act provided a framework for developing professional guidelines enhancing compliance to the criteria allowing euthanasia. Guidelines are increasingly implemented in GP training, postgraduate training, and institutional policy.

\section{Funding body}

The study was funded by the Ministry of Health.

\section{Competing interests}

The authors have stated that there are none.

\section{Acknowledgements}

We would like to thank all GPs from the Dutch Sentinel Network for their contributions to the study. We thank Mrs M Heshusius for her crucial role in the data collection process.

\section{Discuss this article}

Contribute and read comments about this article on the Discussion Forum: http://www.rcgp.org.uk/bjgp-discuss

\section{REFERENCES}

1. Marquet RL, Bartelds A, Visser GJ, et al. Twenty five years of requests for euthanasia and physician assisted suicide in Dutch general practice: trend analysis. BMJ 2003; 327(7408): 201-202.

2. Emanuel EJ, Fairclough DL, Emanuel LL. Attitudes and desires related to euthanasia and physician-assisted suicide among terminally ill patients and their caregivers. JAMA 2000; 284(19): 2460-2468.

3. Hall S, Longhurst S, Higginson I. Living and dying with dignity: a qualitative study of the views of older people in nursing homes. Age Ageing 2009; 38(4): 411-416.

4. Jansen-van der Weide MC, Onwuteaka-Philipsen BD, van der Wal G. Granted, undecided, withdrawn, and refused requests for euthanasia and physician-assisted suicide. Arch Intern Med 2005; 165(15): 1698-1704.

5. Onwuteaka-Philipsen BD, van der Heide A, Koper D, et al. Euthanasia and other end-of-life decisions in the Netherlands in 1990, 1995 and 2001. Lancet 2003; 362(9381): 395-399.

6. Janssen A. The new regulation of voluntary euthanasia and medically assisted suicide in the Netherlands. Int J Law Policy Family 2002; 16(2): 260-269.

7. Van der Heide A, Onwuteaka-Philipsen BD, Rurup ML, et al. Endof-life practices in the Netherlands under the Euthanasia Act. N Engl J Med 2007; 356(19): 1957-1965.

8. Rietjens J, van Delden J, Onwuteaka-Philipsen B, et al. Continuous deep sedation for patients nearing death in the Netherlands. BMJ 2008; 336(7648): 810-813.

9. Donker GA. Continuous morbidity registration at Dutch Sentinel stations 2008. Utrecht: NIVEL, 2009. http://www.nivel.nl/peilstations (accessed 23 Feb 2009).

10. Donker GA, Spreeuwenberg P, Bartelds AIM, et al. Hormone replacement therapy: changes in frequency and type of prescription by Dutch GPs during the last decade of the millennium. Fam Pract 2000; 17(6): 508-513.

11. Marquet RL, Bartelds AIM, Kerkhof AJFM, et al. The epidemiology of suicide and attempted suicide in Dutch General Practice. BMC Fam Pract 2005; 6: 45.

12. Paget JW, Marquet RL, Meijer A, van der Velden J. Influenza activity in Europe during eight seasons (1999-2007); an evaluation of the indicators used to measure activity and an assessment of the timing, length and course of peak activity (spread) across Europe. BMC Infect Dis 2007; 7: 141.

13. Fleming DM, Zambon M, Bartelds AIM, de Jong JC. The duration and magnitude of influenza epidemics: a study of surveillance data from sentinel general practices in England, Wales and the Netherlands. Eur J Epidemiol 1999; 15(5): 467-473.

14. Van der Velden LF, Francke AL, Hingsman L, Willems DL. Dying from cancer and other chronic diseases in the Netherlands: ten year-trends derived from death certificate data. BMC Palliat Care 2009; 8: 4.

15. Rietjens JA, van Delden JJ, van der Heide A, et al. Terminal sedation and euthanasia: a comparison of clinical practices. Arch Intern Med 2006; 166(7): 749-753.

16. Agrawal M, Emanuel EJ. Death and dignity: dogma disputed. Lancet 2002; 360(9350): 1997-1998.

17. Gordijn B, Janssens R. Euthanasia and palliative care in the Netherlands: analysis of the latest developments. Health Care Anal 2004; 12(3): 195-207.

18. Onwuteaka-Philipsen BD, Gevers JKM, Van der Heide A, et al. Evaluatie wet toetsing levensbeëindiging op verzoek en hulp bij zelfdoding. [Evaluation Euthanasia Act]. Den Haag: ZonMW, 2007. Programma evaluatie regelgeving: deel 23. 